
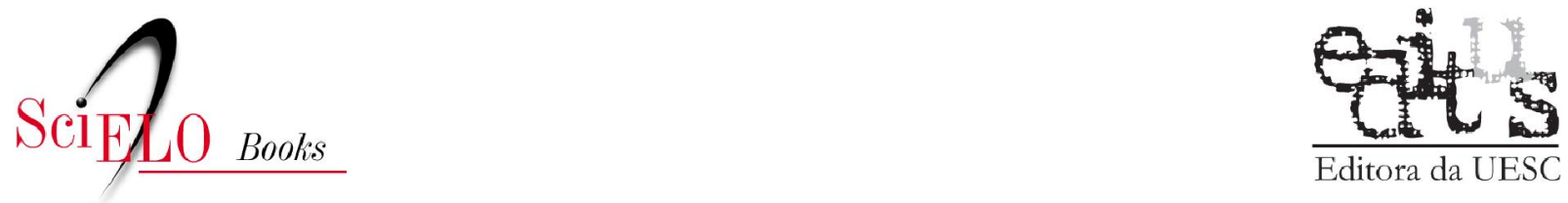

Editora da UESC

\title{
6 - Estado da arte sobre a taxonomia e filogenia de Ponerinae do Brasil
}

\author{
John E. Lattke
}

SciELO Books / SciELO Livros / SciELO Libros

LATTKE, JE. Estado da arte sobre a taxonomia e filogenia de Ponerinae do Brasil. In: DELABIE, JHC., et al., orgs. As formigas poneromorfas do Brasil [online]. Ilhéus, BA: Editus, 2015, pp. 55-73.

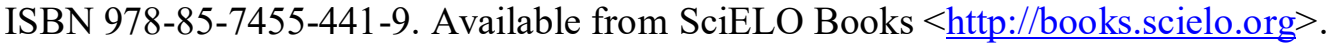

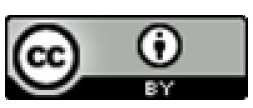

All the contents of this work, except where otherwise noted, is licensed under a Creative Commons Attribution 4.0 International license.

Todo o conteúdo deste trabalho, exceto quando houver ressalva, é publicado sob a licença Creative Commons Atribição 4.0.

Todo el contenido de esta obra, excepto donde se indique lo contrario, está bajo licencia de la licencia Creative Commons Reconocimento 4.0. 


\section{Estado da arte sobre a taxonomia e filogenia de Ponerinae do Brasil}

John E. Lattke

\section{Resumo}

A subfamília Ponerinae tem historicamente recebido muita atenção por sua condição de "caçadoras primitivas", sua morfologia e biologia. O fato de habitarem principalmente florestas úmidas tropicais as converteu em um ícone de biodiversidade tropical para os estudiosos de formigas, especialmente por conta de nosso desconhecimento a respeito deste tema. Estes estudos têm permitido esclarecer muito a respeito de outras formigas, embora também nos tenha feito conscientes do quanto ainda há por fazer.

Entre as subfamílias de formigas, as poneríneas ocupam o quarto lugar em riqueza, com cerca de 1.195 espécies em 47 gêneros, com uma distribuição cosmopolita, mas principalmente tropical. A maioria das espécies foi descrita para a Região Indo-Malaia, seguida pela África e com o Neotrópico em terceiro lugar. Esta mesma ordem também se mantém tanto para o número de gêneros como para o número de espécies endêmicas em cada região. Um destes gêneros, Platythyrea, representa o único gênero dentro da tribo Platythyreini, enquanto todos os demais gêneros são parte da tribo Ponerini. No Brasil, a subfamília conta com 15 gêneros e mais de 130 espécies, o que representa mais de $80 \%$ da diversidade genérica e $40 \%$ diversidade específica conhecida para a América Tropical. Os gêneros Anochetus, Hypoponera, Leptogenys e Odontomachus englobam mais de dois terços da riqueza específica da subfamília.

Inferências fundamentadas em dados moleculares sobre a cronologia das divergências apontam o surgimento das primeiras poneríneas durante o Cretáceo Superior com um evento posterior de diversificação importante próximo ao final do Cretáceo. A diversificação continuou durante o Cenozoico, caracterizando-se por radiações de riqueza em nível regional e intercâmbios faunísticos frequentes entre as grandes regiões biogeográficas. Filogeneticamente, além de vários grupos "basais", se reconhecem dois grandes clados dentro das formigas: o clado poneroide e o clado formicoide, este último muito mais rico em espécies que os poneroideos.

Estas formigas podem ser reconhecidas observando-se as margens laterais dos lobos frontais que, em vista frontal, formam semicírculos curtos ou triângulos rombudos que convergem fortemente posteriormente. No mesossoma,

LATTKE, John E. Estado da arte sobre a taxonomia e filogenia de Ponerinae do Brasil. In: DELABIE, Jacques H. C. et al. As formigas poneromorfas do Brasil. Ilhéus: Editus, 2015. p. 55-73. 
a sutura promesonotal é flexível, o gáster forma uma estrutura contínua a partir do segmento abdominal III e usualmente há uma constrição entre os segmentos abdominais III e IV. Os espiráculos dos segmentos abdominais V-VII não são visíveis sem que o gáster esteja distendido, já que cada um está coberto pela margem posterior do tergo anterior. O ferrão é bem desenvolvido e funcional.

As operárias são parecidas entre si, não existe uma casta de soldados como em outras formigas, também há pouca diferenciação entre as operárias e a rainha, e a presença de reprodutoras com forma de operárias (ergatoides) ou mesmo operárias reprodutoras (gamergates) é comum. As colônias são relativamente pequenas comparadas a outras formigas e os ninhos são pouco elaborados, usualmente localizados na serapilheira, madeira em decomposição, sob raízes ou coberturas de vegetação, sob rochas e árvores.

As Ponerinae são predadoras, usualmente caçando solitariamente, mas algumas desenvolveram forrageamento em grupo, de forma semelhante às formigas de correição. São encontradas predadoras generalistas, embora muitas possuam um elevado grau de especialização com respeito à presa; característica visível particularmente na morfologia mandibular. De fato, as rainhas, ao fundar um ninho, devem sair para caçar de forma a poder alimentar as primeiras larvas, as quais devem ser posicionadas diretamente sobre a presa.

\section{Abstract}

State of the art of the taxonomy and phylogeny of the subfamily Ponerinae - Ants of the subfamily Ponerinae have long received attention due to their role as "primitive predators", as well as their morphology and biology, which is considered simple and basal. Amongst students of ants, they have become an icon of tropical biodiversity due to their preference for tropical rain forests and also because relatively little is known about them. The ensuing studies have shed much light, when compared with other ants, but they have also have made us aware that there is still much to do.

Amongst the ant subfamilies, ponerines occupy fourth place in terms of richness, with some 1195 species placed in 47 genera; they are cosmopolitanly distributed but mostly tropical. Most species have been described from the Indomalaysian Region, followed by Africa, with the Neotropics in third place. This same order is also maintained for the number of genera as well as the amount of endemic species for each region. One of these genera, Platythyrea, is the only genus in the Tribe Platythyreini, whilst all the other genera form part of the Tribe Ponerini. In Brazil 15 genera and over 130 species can be found, a diversity that represents more than $80 \%$ of the genera and $40 \%$ of the species of the American Tropics. More than two-thirds of the species richness in this subfamily is found amongst four genera: Anochetus, Hypoponera, Leptogenys, and Odontomachus.

Inferences about the order of lineage divergences, supported by molecular data, point to the Late Cretaceous as the time for the first ants, with an important burst of diversification close to the end of the Cretaceous. Diversification continued during the Cenozoic, with bouts of regional radiations and frequent faunal exchange between the major biogeographic regions. Besides several "basal" groups, most ants can be phylogenetically divided amongst two large clades: the poneroids and the formicoids, the latter group being by far more species-rich than the poneroids.

Ponerinae can be recognised by observing the shape of the frontal lobes which, in frontal view, form semicircles or blunt angles that strongly converge posteriorly. The mesosoma has a flexible promesonotal suture and the gaster forms a continuous structure after abdominal segment III, frequently with a constriction between abdominal segments III and IV. The spiracles on abdominal segments V-VII are not visible if the gaster is not extended, as each one is covered by the posterior 
margin of the preceding tergite. The sting is welldeveloped and functional.

Workers appear quite similar to each other since there is no soldier caste as in many other ants and there is little morphological difference between workers and the queen. It is not uncommon for reproductives to closely resemble workers (ergatoids), and in some instances workers themselves may take take on this role (gamergates). Colonies are usually modest in size relative to other ants and are rather simple, usually established within the leaf litter, decomposing wood, under roots or under mats of vegetation on rocks or wood.

These ants are predators, usually hunting alone but some have evolved mass group foraging similar to army ants. They can range from generalist predators to exquisitely specialized predators with modifications usually affecting their mandibular morphology. Even nest founding queens must venture forth to hunt if they are to feed their first larvae, which must be positioned directly upon the prey so they may consume it.

\section{Introdução}

As formigas podem dividir-se em dois grandes grupos, o clado formicoide e o clado poneroide. O primeiro é o mais diverso, com aproximadamente $90 \%$ da riqueza da família, e nos $10 \%$ restantes está a subfamília Ponerinae, a terceira mais diversa de Formicidae. Sua história evolutiva remonta desde o Cretáceo Superior, sofrendo uma diversificação significativa próximo ao limite K-T, e divergências contínuas durante o Cenozoico (SCHMIDT, 2013). Entre as poneroides, a subfamília Ponerinae é a mais diversa, com aproximadamente 1.200 espécies divididas entre 47 gêneros (BOLTON, 2014), dos quais 18 gêneros e mais de 330 espécies são conhecidos para o trópico americano e pelo menos 15 gêneros e mais de 130 espécies estão registrados para o Brasil. Os seguintes gêneros englobam quase $70 \%$ das espécies conhecidas: Anochetus, Hypoponera, Leptogenys e Odontomachus.

Estas formigas são principalmente tropicais com preferência por florestas e podem variar em tamanho desde muito pequenas até as maiores formigas viventes. As poneríneas são predadoras que podem variar desde amplamente generalistas até especialistas extremas, o que implica em uma função reguladora das populações de muitos outros grupos de artrópodes e na possibilidade de atuar como indicadores da diversidade dos mesmos. As poneríneas se destacam por, simultaneamente, apresentar uma organização social relativamente simples e generalizada, com um repertório muito diverso de caracteres morfológicos, ecológicos e etológicos derivados. Isto faz destas formigas uma fonte valiosa de oportunidades para o estudo da evolução de caracteres considerados críticos para o êxito de outras linhagens de formigas como as formicíneas e mirmicíneas (SCHMIDT; SHATTUCK, 2014).

A classificação atual é obra de SCHMIDT; SHATTUCK (2014). A subfamília se divide em duas tribos, Platythyreini e Ponerini, esta última, por sua vez, é dividida em seis grupos informais de espécies. Destes grupos, o grupo Pachycondyla é exclusivamente Neotropical e o grupo Harpegnathos é paleotropical; os grupos Ponera e Plectroctena são majoritariamente paleotropicais, exceto por alguns gêneros; o grupo Odontomachus tem mais espécies paleotropicais, mas também uma quantidade considerável de espécies neotropicais. Por último, a diversidade de espécies tanto em Hypoponera como em Platythyrea está dividida de forma mais ou menos equitativa entre o Paleo e o Neotrópico.

Esta subfamília tem chamado a atenção de muitos pesquisadores há muito tempo e por isso conta com muitos recursos para os iniciantes em seu estudo. Contudo, o interessado rapidamente se dará conta que ainda existe um universo de desconhecimento esperando para ser desvendado. Como primeiro recurso temos os trabalhos de Schmidt (2013) e Schmidt; Shattuck (2014), os quais proporcionam fundações filogenéticas e informações de valor incalculável para quem se inicia no estudo destas formigas. O segundo trabalho mencionado, em particular, é uma rica fonte 
de informação biológica para cada um dos gêneros da subfamília e sem dúvida facilitou muito a redação do presente capítulo. Outra obra de cobertura ampla é Jiménez et al. (2008), a qual também oferece muita informação relevante ao estudo das poneríneas brasileiras. Apesar de se concentrar na fauna da Colômbia, as chaves para as espécies dos diferentes gêneros de poneríneas cobrem toda a fauna neotropical. Algumas revisões recentes também oferecem apoio para elucidar a identidade das espécies deste grupo, especialmente em alguns dos gêneros mais ricos, e estas serão citadas ao considerarmos cada um dos gêneros nos parágrafos seguintes.

\section{Subfamília Ponerinae}

Diagnose. O esclerito antenal basal (tórulo) está fundido ao lóbulo frontal e as margens laterais dos lóbulos frontais, em vista frontal, formam semicírculos curtos ou triângulos rombudos que convergem fortemente posteriormente; a antena tem 12 segmentos nas fêmeas e 13 nos machos. No mesossoma a sutura promesonotal é flexível, o orifício da glândula metapleural carece de uma franja ou lóbulo dorsal e a parte posterior do mesossoma apresenta lóbulos propodeais. O segundo segmento abdominal (pecíolo) está unido ao terceiro por uma constrição delgada. Tergo e esterno do segmento abdominal II não estão fundidos, mas os dos segmentos III e IV sim. O gáster forma uma estrutura contínua a partir do segmento abdominal III e usualmente há uma constrição entre os segmentos abdominais III e IV. Os espiráculos dos segmentos abdominais V-VII não são visíveis sem que o gáster esteja distendido, já que cada um está coberto pela margem posterior do tergo anterior. O ferrão é bem desenvolvido e funcional. Esta diagnose se fundamenta na proposta de Bolton (2003).

\section{Gêneros Representados no Brasil}

\section{Anochetus Mayr}

Fig. 6.1

Diagnose. A cabeça é alongada a sub-retangular, com as mandíbulas retas, estreitas e paralelas quando fechadas; a parte póstero-dorsal da cabeça apresenta uma carena transversal fina e arqueada (carena nucal); a superfície dorsal cefálica carece de sulcos amplos e rasos (as chamadas apófises). Frequentemente apresentam dentes propodeais discretos e o pecíolo geralmente apresenta o ápice bidentado. Consulte a diagnose de Odontomachus, muito semelhante, para diferenciá-lo de Anochetus.

Diversidade. São conhecidas 114 espécies na fauna mundial (BOLTON, 2014), das quais 26 são reportadas para a América Tropical e aproximadamente 10 espécies são registradas no Brasil (FERNÁNDEZ; SENDOYA, 2004). O número exato depende da identidade de algumas espécies problemáticas do grupo inermis e do complexo mayri; contudo, esta não deixa de ser uma aproximação

FIGURA 6.1 - Exemplar do Anochetus horridus Kempf, operária. (a) cabeça em vista frontal e (b) corpo em vista lateral. Foto: Will Ericson (Antweb, CASENT0260495).

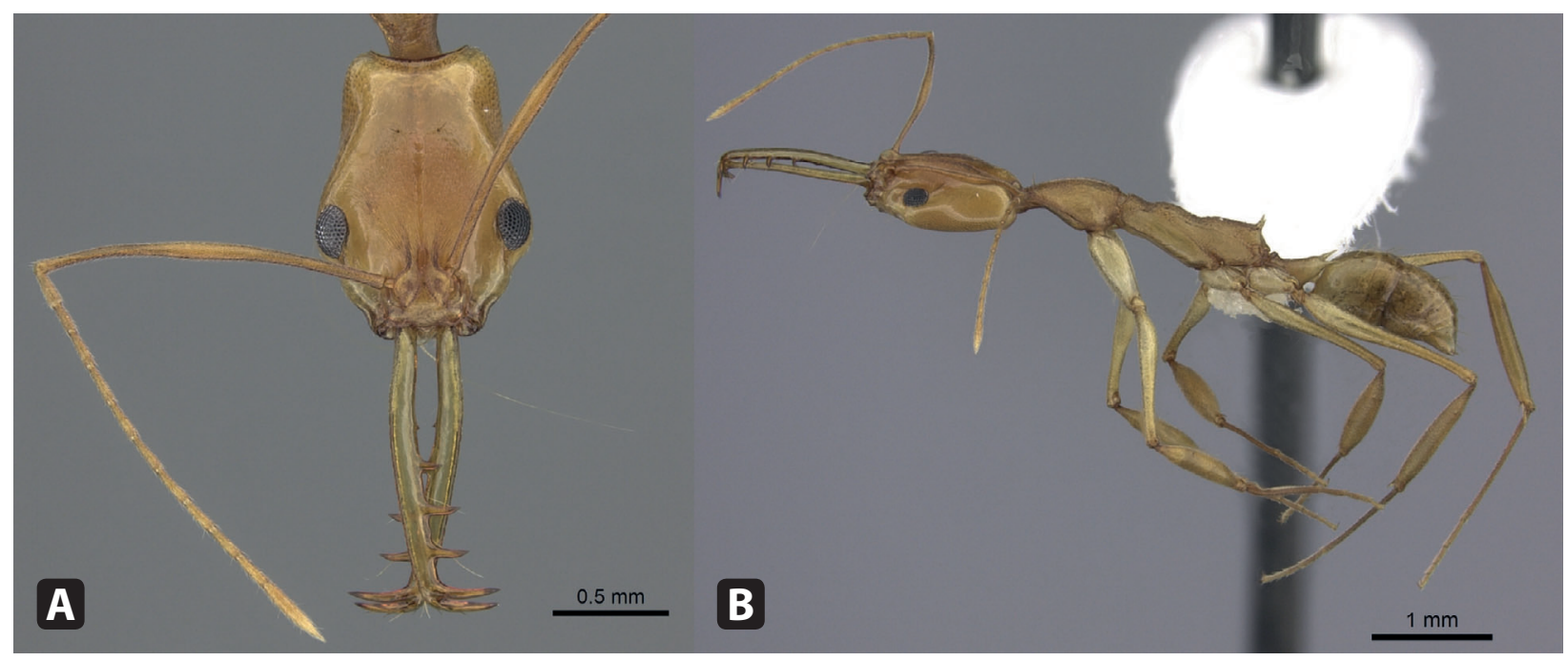


preliminar dado o estado de conhecimento atual. A identificação em nível específico depende da revisão de Brown (1978), complementada por uma chave atualizada por Zabala (FERNANDEZ, 2008). A espécie de maior tamanho do gênero, Anochetus hohenbergiae Feitosa; Delabie, foi recentemente descrita para o Brasil (FEITOSA et al., 2012).

Distribuição. O grupo está presente por toda a geografia nacional, em especial nas áreas de floresta.

Biologia. De maneira similar às formigas do gênero Odontomachus, a predação é por emboscada, com as mandíbulas de fechamento rápido abertas em $180^{\circ}$, as quais impactam a presa ao contato com pelos que servem de gatilho, ligados às peças bucais. Sabe-se pouco sobre as preferências alimentares destas formigas. Os ninhos são feitos na serapilheira, madeira em decomposição, sob troncos caídos, pedras e folhas acumuladas em galhos de árvores e epífitas. Existem espécies diminutas presentes em amostras de serapilheira e solo. Reprodutoras ergatoides aparentemente são comuns e algumas espécies possuem tanto rainhas normais como ergatoides (SCHMIDT; SHATTUCK, 2014). Comparado ao seu grupo-irmão, Odontomachus, sabe-se muito pouco sobre a biologia deste gênero.

Perspectivas. Atualmente a pesquisadora Itanna Oliveira Fernandes está revisando a fauna mundial deste grupo como parte de seus estudos de doutorado. Existem dúvidas se o gênero pode ser considerado diferente de Odontomachus e parte das pesquisas da Ma Fernandes tentará esclarecer a situação.

\section{Centromyrmex Mayr}

Fig. 6.2

Diagnose. Cutícula muito lisa e brilhante e de coloração âmbar a ferruginosa, sem pelos e sem vestígios de olhos; tem o escapo achatado. As meso e metatíbia apresentam pelos espiniformes curtos e grossos na face exterior; sutura metanotal obsoleta. Pecíolo unido ao pós-pecíolo próximo à metade da altura deste último em vista lateral.

Diversidade. Existem umas 15 espécies em nível mundial (BOLTON, 2014), das quais três são conhecidas para o trópico americano, todas elas presentes no Brasil. A identificação pode ser feita com a revisão de Kempf (1967) ou a chave de Fernández (2008).

Distribuição. Está presente em quase todo o país, com a possível exceção dos estados mais ao Sul.

Biologia. A relativa despigmentação, carência de olhos, cutícula polida e a presença de espinhos na meso e metatíbias são caracteres típicos de formigas com hábitos hipogeicos (SCHMIDT; SHATTUCK, 2014). Os ninhos são encontrados no solo, serapilheira, madeira em decomposição e

FIGURA 6.2 - Exemplar do Centromyrmex alfaroi Emery, operária. (a) cabeça em vista frontal e (b) corpo em vista lateral. Foto: April Nobile (Antweb, CASENT0178340).

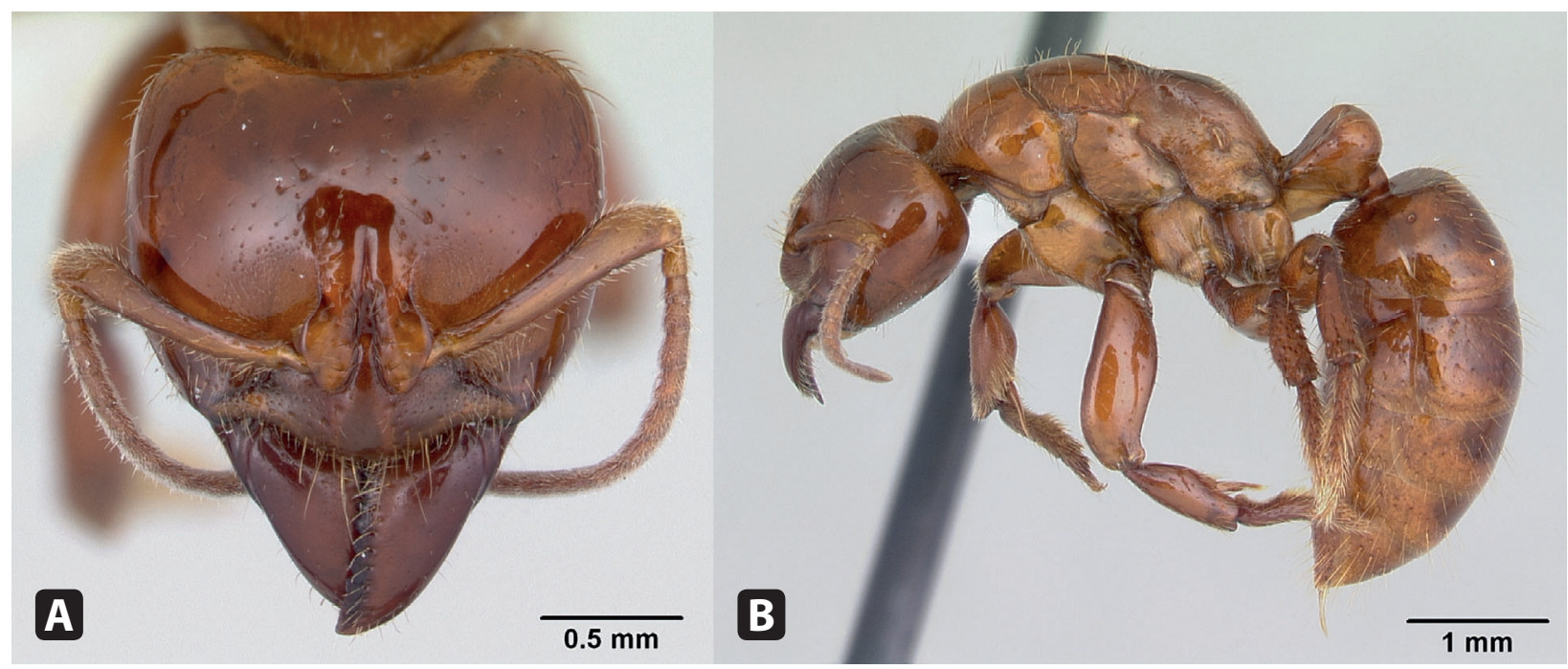


próximo ou dentro de ninhos de cupins. Os cupins são a presa obrigatória destas formigas e uma boa maneira de se coletar formigas deste grupo é buscando em cupinzeiros. De fato, pode haver mais de uma espécie de Centromyrmex presente em um mesmo cupinzeiro (DELABIE, 1995).

Perspectivas. Comparado a outras poneríneas é pouco o que se sabe de sua história natural. Não estão entre as formigas mais coletadas e, por isso, desconhecemos seus padrões de distribuição no país.

\section{Cryptopone Emery}

Fig. 6.3

Diagnose. Os olhos estão muito reduzidos ou ausentes e os escapos são achatados; as mandíbulas usualmente têm uma fosseta latero-basal. As mesotíbias apresentam pelos de tração, os quais são grossos e curtos. A junção entre pecíolo e pós -pecíolo situa-se na porção ventral da face anterior do pós-pecíolo e a cutícula não é brilhante (como em Centromyrmex).

Diversidade. São conhecidas aproximadamente 25 espécies e subespécies para este grupo, a maioria da Ásia. As espécies podem ser identificadas com o trabalho de Mackay; Mackay (2010).

Distribuição. Quatro espécies são reportadas para a América Tropical das quais três (C. guianensis, C. holmgreni e C. mirabilis) são registradas para o
Brasil; contudo, os registros são muito esporádicos e isolados, implicando em grandes lacunas no conhecimento de sua distribuição nacional.

Biologia. A maioria da informação sobre este gênero está associada a C. gilva, espécie encontrada no sul e sudeste dos EUA. Para todas as demais espécies, a informação compilada provém de observações isoladas. A morfologia destas formigas sugere hábitos principalmente subterrâneos e os habitats da maioria dos eventos de coleta corroboram este fato: serapilheira, solo, madeira em decomposição e cupinzeiros. As espécies conhecidas para o país foram coletadas principalmente em habitats de floresta densa.

Perspectivas. É necessário melhorar o conhecimento sobre a distribuição das espécies no país e conhecer a biologia do grupo no Trópico Americano.

\section{Dinoponera Roger}

Fig. 6.4

Diagnose. Entre as maiores formigas do mundo se encontram as deste gênero, com um comprimento corporal maior que $2,5 \mathrm{~cm}$. Apenas com base no tamanho são facilmente distinguíveis de todas as demais formigas. Adicionalmente, têm dois dentes triangulares projetados de cada lado da margem anterior do clípeo e fileiras de setas grossas nas laterais do pigídio e do hipopígio.

FIGURA 6.3 - Exemplar do Cryptopone guianensis (Weber), operária. (a) cabeça em vista frontal e (b) corpo em vista lateral. Foto: Ryan Perry (Antweb, CASENT0249146).

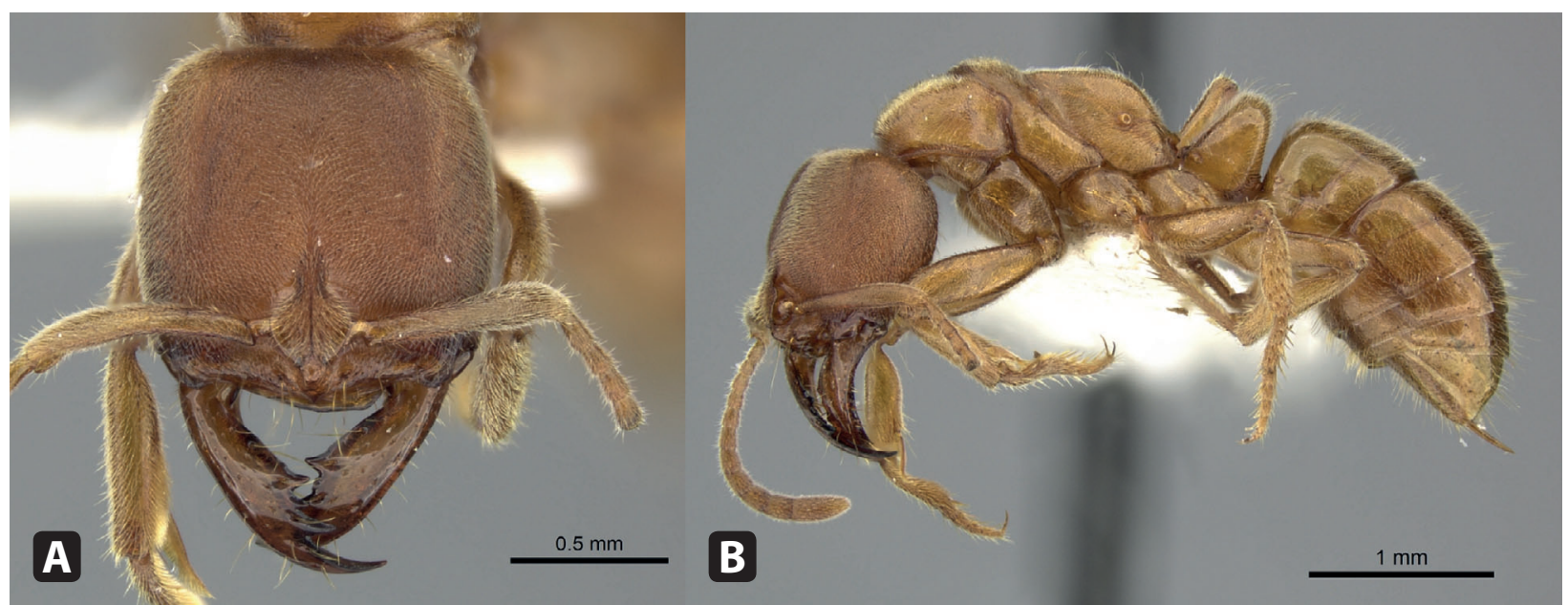


FIGURA 6.4 - Exemplar do Dinoponera quadriceps Kempf, operária. (a) cabeça em vista frontal e (b) corpo em vista lateral. Foto: Shannon Hartmann (Antweb, CASENT0217519).

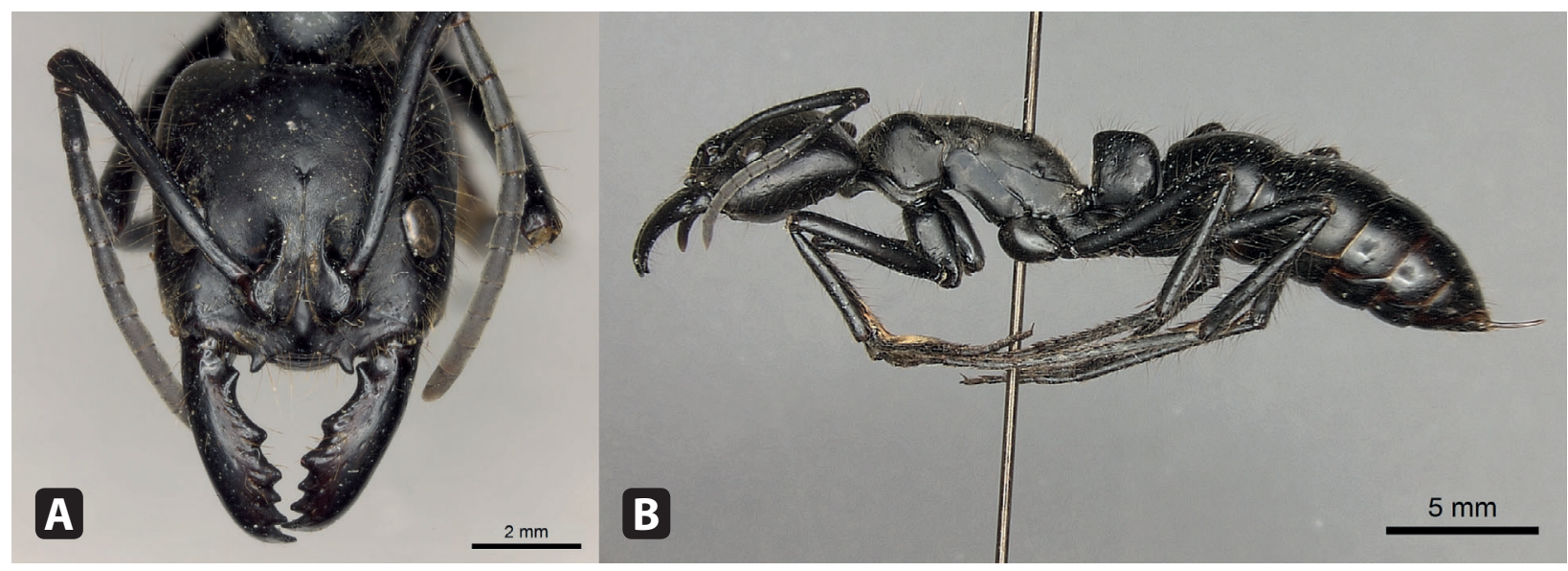

Diversidade. São conhecidas oito espécies e duas subespécies deste gênero exclusivamente sul -americano. Todas as espécies estão presentes no Brasil (LENHART et al., 2013).

Distribuição. O gênero está distribuído por todo o país, com representantes em ambientes de floresta e savanas.

Biologia. As espécies nidificam no solo, em colônias que podem variar de menos de 10 indivíduos até 200 ou mais operárias. A densidade de ninhos em uma localidade pode chegar a 180 por hectare, implicando em um peso úmido de aproximadamente $2,5 \mathrm{~kg} / \mathrm{ha}$, com indícios de forte territorialidade entre as colônias (TILLBERG et al., 2014). A reprodução é por meio de operárias férteis (gamergates) e a competição para o posto de fêmea alfa do ninho é intensa. Uma revisão taxonômica do gênero com um resumo sobre sua biologia foi recentemente publicada por Lenhart et al. (2013).

Perspectivas. Apesar do grande tamanho destas formigas, a revisão recentemente conduzida foi bem sucedida em descobrir novas espécies. Coletas no futuro devem definir melhor o intervalo de distribuição de cada espécie e outros estudos deverão permitir uma melhor compreensão de sua biologia.

\section{Hypoponera Santschi}

Fig. 6.5

Diagnose. Usualmente quando encontramos uma ponerínea de tamanho reduzido e aspecto generalizado pode-se imediatamente suspeitar que se trate de uma Hypoponera. A mandíbula é triangular com uma série de dentículos e sem a presença de fossetas ou sulcos em sua base; os olhos tendem a ser pequenos e situados na parte ântero-lateral da cabeça, em alguns casos podem estar ausentes. O mesossoma apresenta uma sutura metanotal rasa, a metatíbia é provida de um único esporão em seu ápice e não há setas robustas sobre as mesotíbias nem sobre os tarsos médios ou posteriores. $\mathrm{O}$ nódulo peciolar não é volumoso $\mathrm{e}$ sim relativamente plano ântero-posteriormente, com seu processo ventral arredondado, sem dentes ou mancha translúcida.

Diversidade. Mundialmente o gênero conta com quase 150 espécies (BOLTON, 2014), das quais cerca de 52 são conhecidas para a América e pelo menos umas 20 estão presentes no Brasil (FERNÁNDEZ; SENDOYA, 2004).

Distribuição. Está presente em todos os continentes, inclusive em regiões temperadas, com a exceção da Antártida. Várias espécies foram introduzidas por todo o mundo através das atividades humanas, como $H$. punctatissima, a ponerínea com a maior distribuição conhecida, também presente no Brasil (DELABIE; BLARD, 2002), que, contudo, pode se tratar de $H$. ergatandria segundo Seifert (2013). Estas formigas podem ser encontradas principalmente em florestas, onde estão entre as formigas mais comuns tanto na serapilheira como no solo, mas também estão presentes em locais perturbados.

Biologia. Estas formigas são majoritariamente predadoras generalistas até onde se sabe e os ninhos podem ser encontrados na serapilheira, solo, 
FIGURA 6.5 - Exemplar do Hypoponera distinguenda (Emery), operária. (a) cabeça em vista frontal e (b) corpo em vista lateral. Foto: April Nobile (Antweb, CASENT0173712).

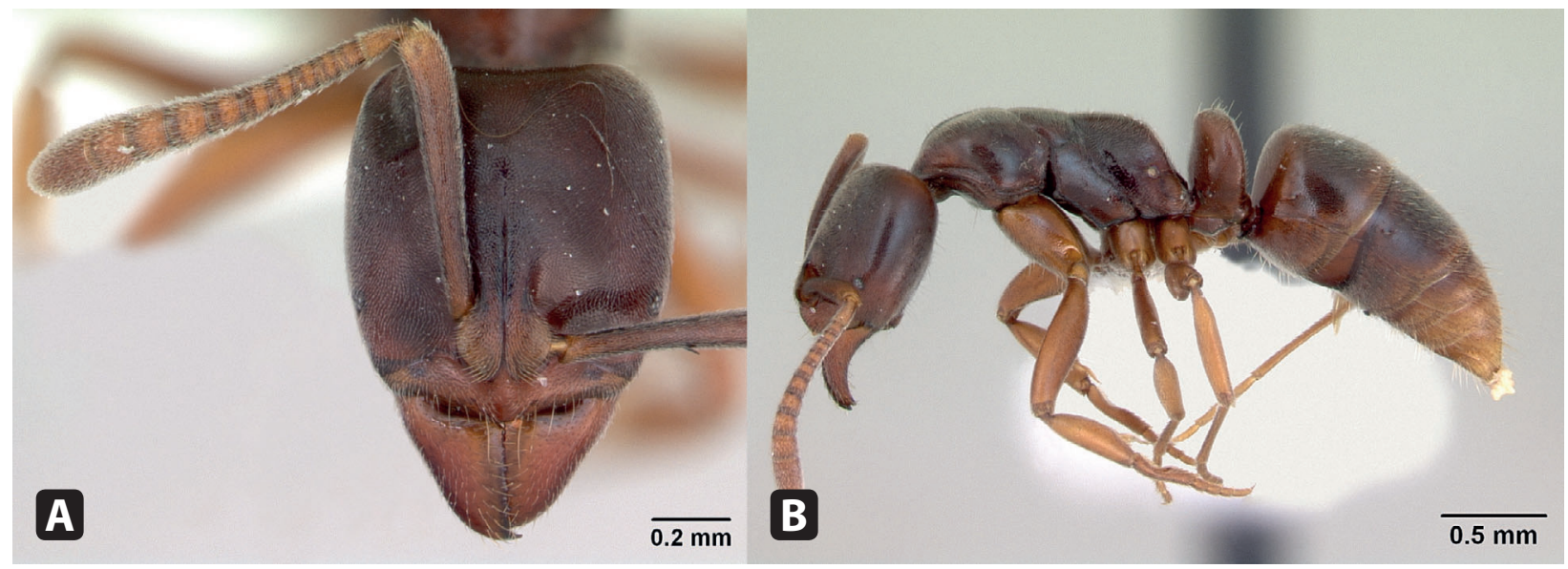

madeira em decomposição sobre o solo e sob rochas. A vida reprodutiva de algumas espécies é fascinante e variada com a presença de diferentes variedades aladas e intermórficas, tanto de rainhas quanto de machos (SCHMIDT; SHATTUCK, 2014). Algumas espécies possuem machos ergatoides, os quais lutam e se matam entre si para copular com as fêmeas.

Perspectivas. Dado o tamanho reduzido da maioria das espécies e seus hábitos crípticos, é pouco o que sabemos do gênero. A variação morfológica de algumas das espécies faz de sua taxonomia um desafio e quase torna obrigatório o uso de métodos moleculares. A ausência de uma revisão formal para a fauna americana implica que a taxonomia alfa é um mistério para a maioria das espécies e uma prova incontestável é a quantidade de estudos faunísticos nos quais a maioria das espécies de Hypoponera não passa de "sp. 1" até "sp. n". Felizmente existe uma revisão potencial da fauna americana, mas ainda em formato de tese, feita por S. Dash, em 2011, sob a orientação do Dr. William Mackay, mas lamentavelmente ainda não foi submetida a uma revisão por pares e publicada formalmente. Vale destacar que na tese mencionada não foram consultados exemplares de nenhuma coleção brasileira, o que sugere que falta muito trabalho a ser feito quanto à taxonomia e distribuição das espécies, sem mencionar sua biologia.

\section{Leptogenys Roger}

Fig. 6.6

Diagnose. A forma cefálica varia desde alongada até mais larga do que longa em vista frontal; olho composto usualmente situado anterior à metade da cabeça, variando desde com poucos omatídeos até grande e semiesférico, ocupando um terço da margem lateral da cabeça. Mandíbulas triangulares a subtriangulares, frequentemente alongadas e com as margens interna e externa quase paralelas, incapazes de tocar o clípeo quando fechadas. Clípeo relativamente longo, com sua porção média projetando-se anteriormente como um lóbulo mais ou menos triangular, quase sempre com uma crista longitudinal que vai desde o ápice do clípeo até o nível dos lobos frontais. Espiráculo propodeal separado da margem declive por pelo menos três vezes seu diâmetro. Primeiro segmento pretarsal sem uma faixa de setas robustas do lado oposto ao esporão; garras tarsais pectinadas (pente às vezes reduzido em espécies pequenas); arólio ausente. Gáster usualmente liso e brilhante.

Diversidade. Trata-se do gênero mais diverso da subfamília, com mais de 300 espécies conhecidas mundialmente até agora (BOLTON, 2014). Nas Américas há pelo menos 81 espécies, das quais 19 se encontram no Brasil (LATTKE, 2011), incluindo L. maxillosa, espécie de origem africana introduzida pela atividade humana.

Distribuição. Representantes do gênero estão presentes por toda a geografia nacional; contudo, são poucos os exemplares em coleções e normalmente das mesmas espécies, o que implica em uma subestimação do intervalo de distribuição destas espécies. Leptogenys maxillosa está registrada para Pernambuco e São Paulo, ambas as localidades com forte atividade portuária e comercial, 
FIGURA 6.6 - Exemplar do Leptogenys unistimulosa Roger, operária. (a) cabeça em vista frontal e (b) corpo em vista lateral. Foto: April Nobile (Antweb, CASENT0178818).

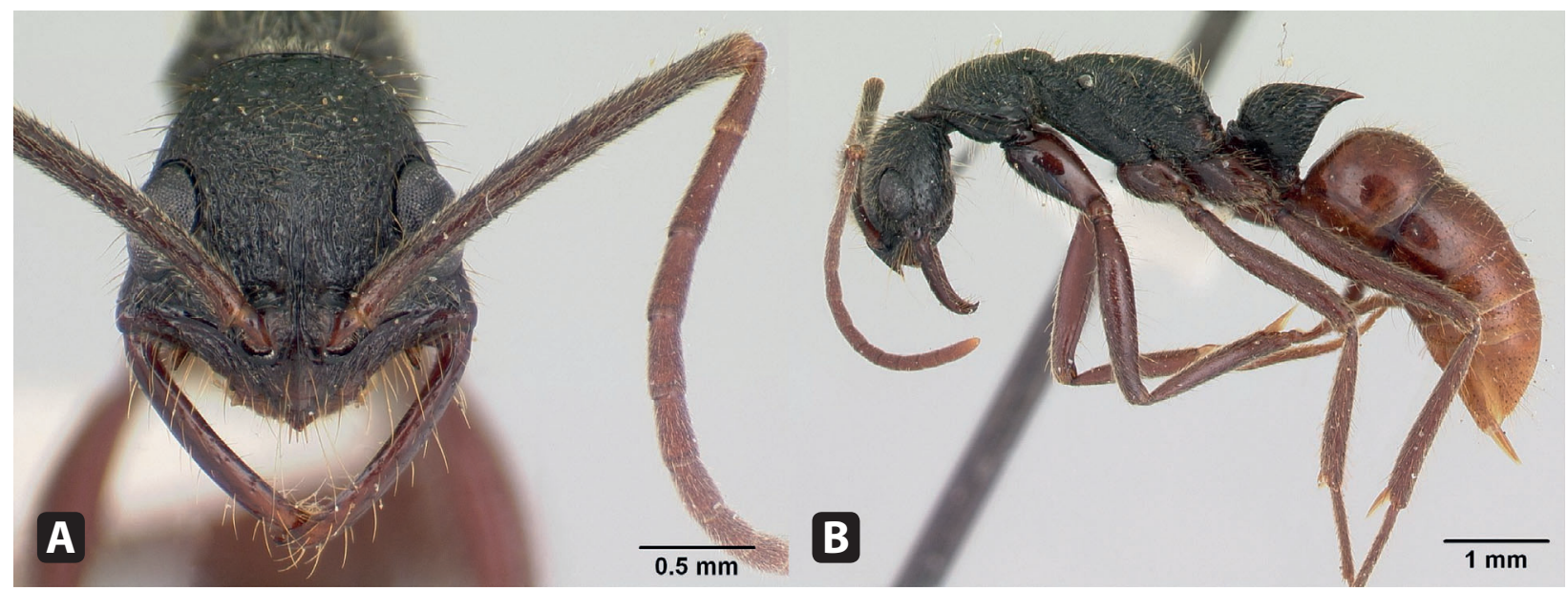

condições favoráveis para a propagação de espécies invasoras. Não há registros suficientes para discernir padrões com muita confiabilidade, exceto pelo reconhecimento de uma fauna amazônica composta por espécies como L. amazonica, $L$. famelica, L. gaigei, L. guianensis, L. langi, L. linearis, L. nigricans e L. unistimulosa. Há um grupo de espécies conhecido apenas da Mata Atlântica do Sudeste do país, com espécies como L. australis, $L$. bohlsi, L. crudelis e L. vogeli. Os habitats favoritos são florestas úmidas, embora algumas espécies tenham conseguido se estabelecer em matas secas.

Biologia. São predadoras com uma tendência à especialização, em particular em isópodes terrestres. $\mathrm{O}$ forrageamento é feito individualmente ou em pequenos grupos, mas não em massa como em algumas espécies paleotropicais do gênero. Os ninhos são feitos ao nível do solo, usualmente em madeira em decomposição, sob pedras e entre fissuras em rochas e troncos. Não há espécies arbóreas como em algumas outras poneríneas (Neoponera ou Anochetus). Os ninhos podem conter algumas centenas de operárias em alguns casos até poucas dezenas. A reprodução usualmente se dá por meio de rainhas ergatoides e em alguns casos com operárias férteis (gamergates). Em apenas três ou quatro espécies da América Tropical são conhecidas rainhas com a morfologia torácica típica e mesmo nestes casos são apenas rainhas sem asas. Não se conhece nenhum exemplar alado de Leptogenys, pelo menos na América. Seus hábitos noturnos e a surpreendente velocidade de muitas das espécies dificultam sua coleta, o que explica a relativa escassez de exemplares nas coleções nacionais em comparação com as demais poneríneas.

Perspectivas. Apesar de contar com uma revisão relativamente recente para a fauna americana (LATTKE, 2011), falta muito para se conhecer sobre este grupo de formigas. Existem muitas lacunas na distribuição das espécies conhecidas, por exemplo, L. corniculans só é conhecida por um único exemplar da Bahia e sem dúvida ainda faltam muitas espécies a serem descobertas, dada a distribuição relativamente restrita de muitas. Há uma filogenia preliminar para as espécies americanas, mas esta necessita de uma melhor resolução e complemento de dados moleculares.

\section{Mayaponera Schmidt; Shattuck Fig. 6.7}

Diagnose. São formigas relativamente esbeltas com um comprimento aproximado de 5 $\mathrm{mm}$, reconhecíveis pelo profundo sulco metanotal o mesonoto de forma convexa bem evidente, além de apresentarem o propódeo com uma superfície dorsal estreita e com um sulco longitudinal. Os espiráculos propodeais são redondos.

Diversidade. Apenas uma espécie conhecida, Mayaponera constricta (Mayr), a qual até recentemente era considerada uma Pachycondyla.

Distribuição. Presente em toda a geografia nacional, alcançando seus limites austrais no estado de São Paulo. 
FIGURA 6.7 - Exemplar do Mayaponera constricta (Mayr), operária. (a) cabeça em vista frontal e (b) corpo em vista lateral. Foto: Ryan Perry (Antweb, CASENT0249137).

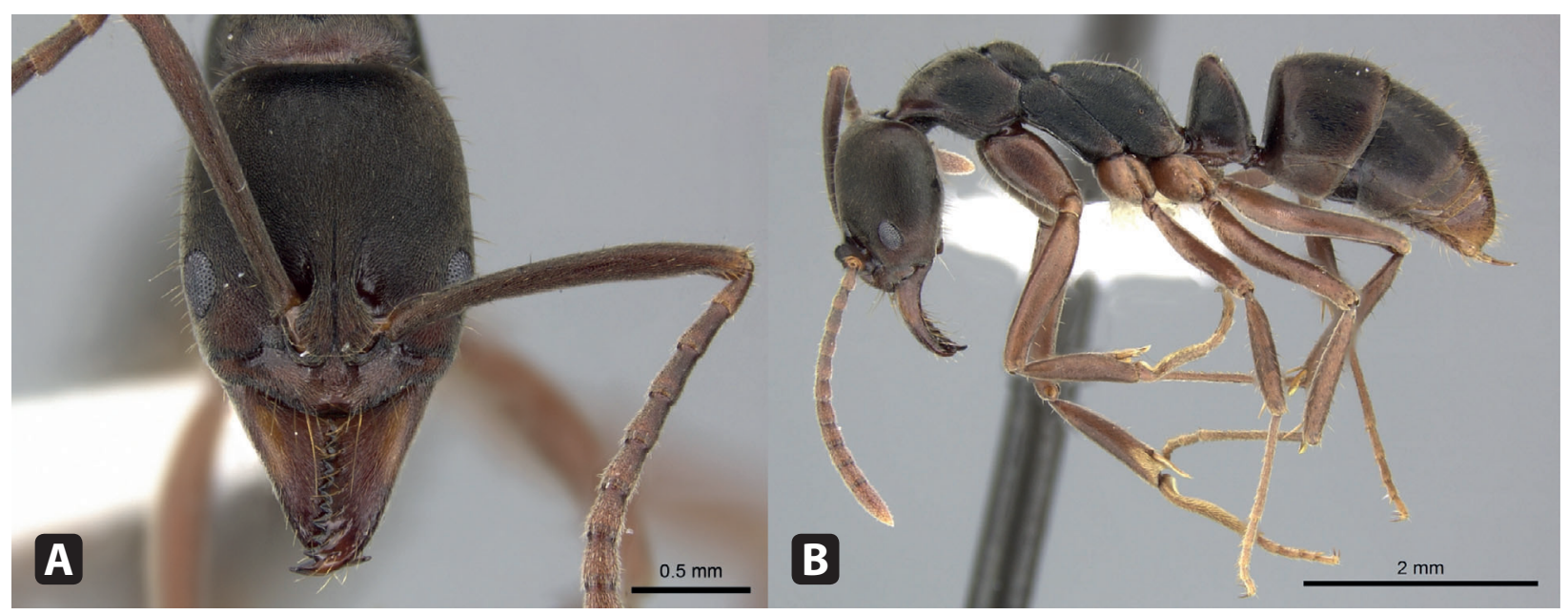

Biologia. Está presente em ambientes de floresta tanto naturais como perturbadas, mesmo as de uso agrícola, como cafezais e cacauais. Os ninhos estão ao nível do solo, em madeira decomposta ou sob pedras. Informações adicionais sobre sua biologia podem ser consultadas em Schmidt; Shattuck (2014) ou Mackay; Mackay (2010).

\section{Neoponera Emery}

Fig. 6.8

Diagnose. Olhos relativamente grandes, convexos e situados na parte média da cabeça; com frequência apresentam uma carena entre a borda anterior dos olhos e o clípeo (carena pré-ocular). Orifício da glândula metapleural com uma borda saliente em forma de "U" invertido e com um sulco em sua porção ventral. Garras tarsais com um arólio. Entre os segmentos abdominais III e IV podese observar um estridulito na forma de uma franja longitudinal estreita sobre o dorso que reflete a luz; o último tergito abdominal não apresenta uma fileira de setas robustas em cada lado do ferrão.

Diversidade. Este gênero exclusivamente neotropical contém 57 espécies (BOLTON, 2014), das quais pelo menos 35 estão presentes no Brasil. Previamente estas formigas eram consideradas como Pachycondyla. As espécies brasileiras podem ser identificadas com o trabalho de Mackay; Mackay (2010).

Distribuição. Espécies representantes do gênero podem ser encontradas em todo o país. De fato, algumas espécies, como Neoponera villosa, têm uma distribuição que cobre todo o território nacional e chegam até o sul do Texas ao norte e até norte da Argentina ao sul de sua distribuição. Os habitats preferidos são florestas, ao nível do solo ou em árvores.

Biologia. As espécies deste gênero são predadoras, algumas das quais forrageiam sobre o solo, com uma grande parte apresentando hábitos arbóreos, com ninhos em galhos ocos, serapilheira suspensa e em epífitas. Há um grupo de espécies que realiza seu forrageamento em colunas, ao estilo das dorilíneas, embora seus ninhos sejam perenes. Algumas espécies apresentam ninhos poligínicos, como também supressão da reprodução das operárias por parte das rainhas, além de hierarquias de dominância (SCHMIDT; SHATTUCK, 2014). Há pelo menos um caso documentado de deslocamento de caracteres que implica no estridulito, no qual espécies aparentadas desenvolvem morfologias e senhas acústicas diferentes quando em simpatria, mas não quando estão em alopatria (FERREIRA et al., 2010).

Perspectivas. A biologia destas espécies é bem diversa, mas apenas algumas espécies do grupo apicalis foram estudadas detalhadamente. A descoberta de um complexo de espécies crípticas no grupo sugere que a taxonomia das espécies conhecidas pode ser refinada (FERNANDES et al., 2014). Espera-se que uma intensificação de coletas permita a descoberta de espécies adicionais e uma melhora na resolução dos intervalos de distribuição. 
FIGURA 6.8 - Exemplar do Neoponera verenae Forel, operária. (a) cabeça em vista frontal e (b) corpo em vista lateral. Foto: April Nobile (Antweb, CASENT0178187).

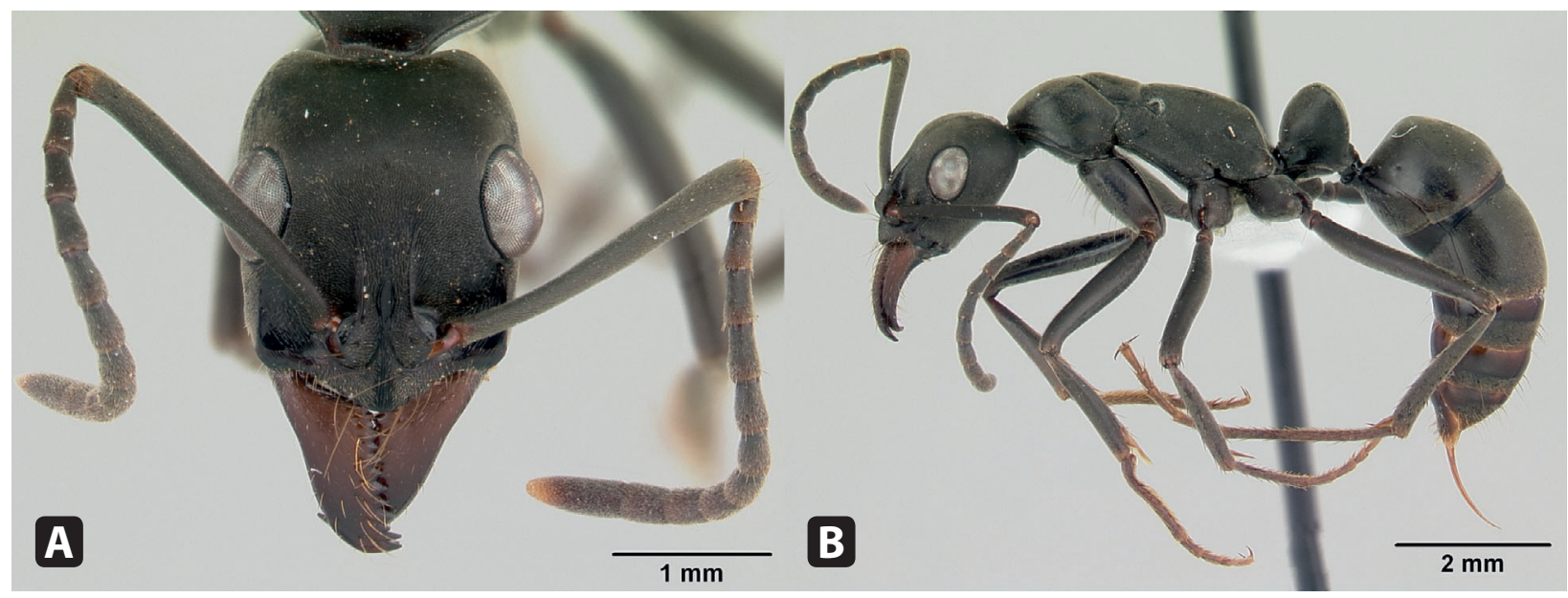

\section{Odontomachus Latreille}

Fig. 6.9

Diagnose. A cabeça é alongada a sub-retangular, com as mandíbulas retas, estreitas e paralelas quando fechadas; a parte póstero-dorsal da cabeça apresenta uma carena fina em forma de "V" que adentra na superfície dorsal cefálica, que por sua vez possui sulcos amplos e rasos (apófises). O propódeo não possui dentes, como é usual em Anochetus e o pecíolo apresenta um dente no ápice. Segmentos abdominais III e IV não são separados pela constrição típica das poneríneas. Consulte a diagnose do gênero Anochetus, muito próximo, para diferenciá-lo de Odontomachus.
Diversidade. O gênero conta com 67 espécies em todo o mundo (BOLTON, 2014), das quais 26 são da América e pelo menos 15 se encontram no Brasil (FERNÁNDEZ; SENDOYA, 2004). As espécies podem ser identificadas com a revisão de BROWN (1976). A chave ilustrada de J. Rodriguez, em Fernández (2008), também é útil já que se baseia na chave de Brown, mas é mais fácil de usar.

Distribuição. Representantes do gênero podem ser encontrados em todo o Brasil, incluindo o extremo sul, já que o gênero chega à Argentina.

Biologia. As espécies tendem a preferir áreas de floresta, onde nidificam sobre o solo, sob

FIGURA 6.9 - Exemplar do Odontomachus bauri Emery, operária. (a) cabeça em vista frontal e (b) corpo em vista lateral. Foto: April Nobile (Antweb, CASENT0173535).

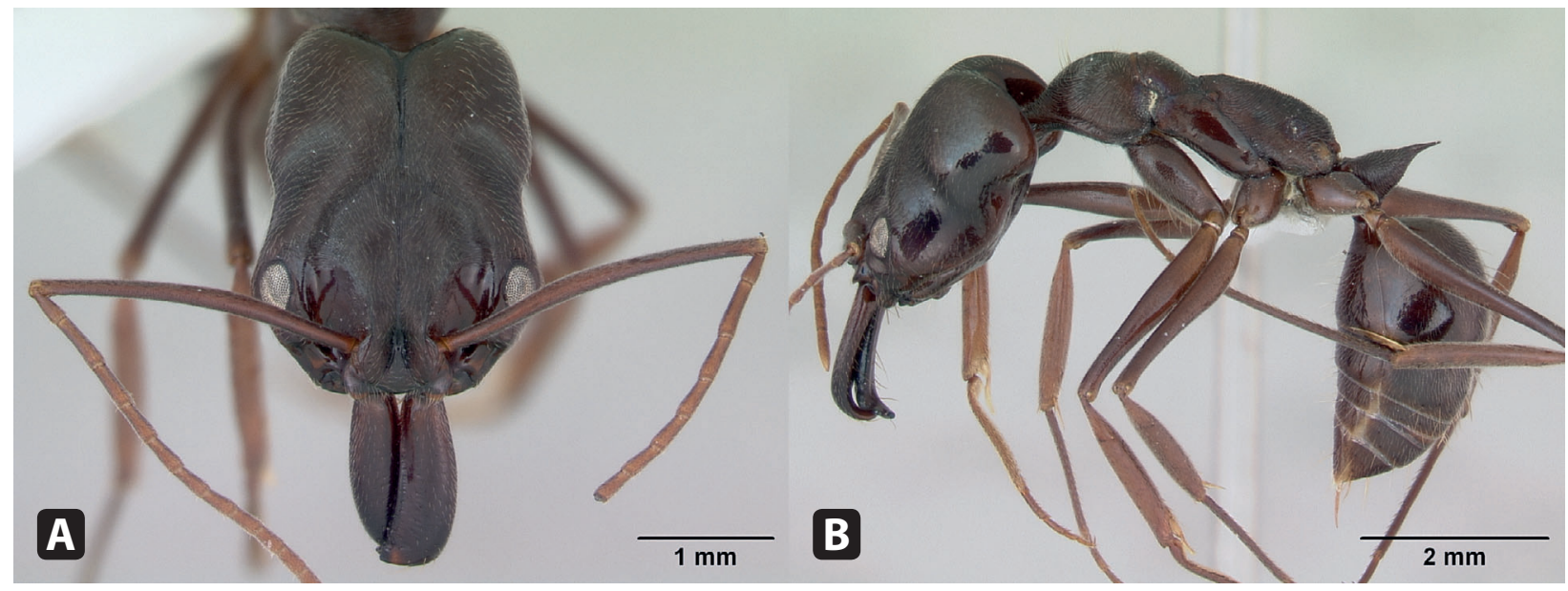


troncos em decomposição e serapilheira, enquanto outras são arbóreas. Algumas espécies estão adaptadas a habitats perturbados e podem ser encontradas em jardins e praças de zonas urbanas, como ocorre com O. bauri. São principalmente predadoras, mas podem explorar secreções em nectários e frutas. A morfologia mandibular deste gênero, assim como a de Anochetus, é altamente especializada e estudos indicam que o fechamento das mandíbulas nestes gêneros é um dos reflexos mais rápidos conhecidos no reino animal. A força cinética do golpe é capaz de matar ou ferir substancialmente sua presa. Uma extensa informação sobre a biologia destas formigas se encontra em Schmidt; Shattuck (2014) e Fernández (2008).

Perspectivas. São conhecidas várias espécies não descritas em coleções mirmecológicas e também é necessária uma melhor resolução dos padrões de distribuição de várias espécies no país. Muito tempo se passou desde a revisão de Brown para que uma nova revisão do gênero seja oportuna. A identidade de Odontomachus como um gênero diferente de Anochetus é atualmente tema de estudo.

\section{Pachycondyla Smith, F.}

\section{Fig. 6.10}

Diagnose. Mandíbula triangular; margem anterior do clípeo sem projeções em forma de dente ou lóbulo; olhos de tamanho médio, nem muito reduzidos e nem muito grandes e convexos.
Mesossoma em vista lateral com o perfil dorsal relativamente contínuo, com a sutura metanotal estreita e rasa; espiráculo propodeal em forma de fenda; orifício da glândula metapleural com uma franja posterior em forma de "U" invertido; garras tarsais simples com um arólio discreto. Nódulo peciolar largo e sub-quadrado; estridulito ausente entre os tergos abdominais III e IV; último esterno abdominal apresenta uma fileira de setas robustas de cada lado do ferrão.

Diversidade. Bolton (2014) reconhece 25 espécies para o gênero, mas Schmidt; Shattuck (2014) reconhecem 11 espécies, além de seis adicionais ainda de posição incerta no gênero. No Brasil existem pelo menos oito espécies (MACKAY; MACKAY, 2010).

Distribuição. A distribuição do gênero depende de quais espécies são consideradas. O grupo é exclusivamente americano, sendo encontrado do sul dos EUA até o norte da Argentina, incluindo o Caribe, mas das seis espécies de posição ainda incerta, duas são neotropicais, três asiáticas e uma de Madagascar. Há 17 espécies fósseis descritas como Pachycondyla, a grande maioria da Europa. A espécie $P$. harpax é uma das poneríneas de maior distribuição, encontrada dos EUA ao norte da Argentina.

Biologia. São formigas predominantemente de áreas de floresta, com os ninhos feitos no solo. É pouca a informação biológica existente sobre estas

FIGURA 6.10 - Exemplar do Pachycondyla impressa (Roger), operária. (a) cabeça em vista frontal e (b) corpo em vista lateral. Foto: April Nobile (Antweb, CASENT0178689).

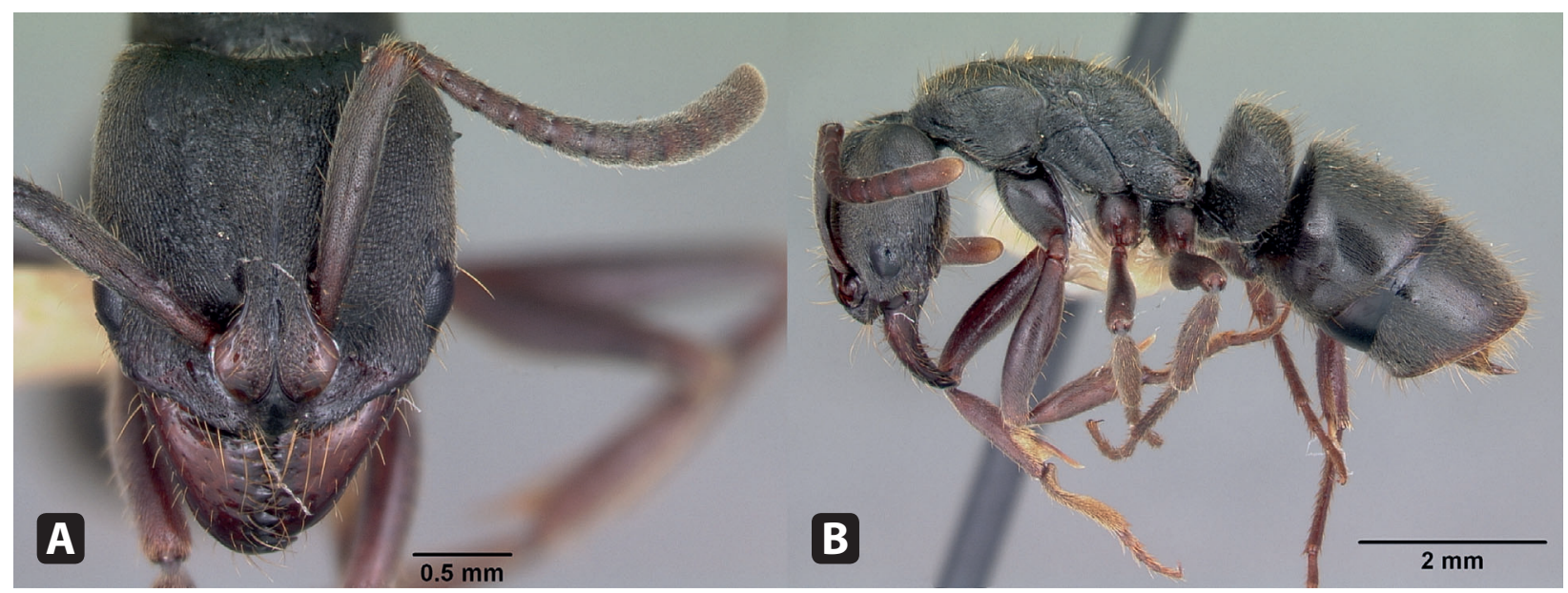


formigas, apesar do fato de existirem espécies com distribuição em dois continentes, América do Norte e América do Sul.

Perspectivas. Schmidt; Shattuck (2014) deixam claro que não existe uma apomorfia para sustentar a monofilia do grupo e também há várias espécies, existentes e fósseis, que não podem ser seguramente incluídas em Pachycondyla. Estudos sobre a biologia de algumas espécies seria desejável, em especial espécies como $P$. harpax ou $P$. impressa para determinar se são espécies ou complexos de espécies.

\section{Platythyrea Roger}

Fig. 6.11

Diagnose. Entre as poneríneas, são formigas fáceis de reconhecer por sua combinação de caracteres. A primeira vista chama a atenção o tegumento opaco e de aspecto finamente granuloso, como uma lixa de calibre mais fino e sem pelos eretos sobre o corpo. As mandíbulas são triangulares e o clípeo, diferente de outras poneríneas, se insere de maneira muito ampla entre os lobos frontais. A glândula metapleural se abre lateralmente; a metatíbia termina em dois esporões e as garras tarsais são dentadas. Pecíolo inserido na altura da metade da face anterior do terceiro segmento abdominal em vista lateral.

Diversidade. São reconhecidas 38 espécies para este gênero (BOLTON, 2014), das quais 13 são americanas (nove existentes e quatro extintas), sendo cinco registradas no Brasil, segundo Fernández; Sendoya (2004) e DE ANDRADE (2004). Os trabalhos mencionados têm chaves para identificação das espécies americanas; contudo, a chave de DE ANDRADE (2004) inclui uma espécie adicional além de todas as extintas.

Distribuição. Platythyrea tem distribuição Pantropical, e no Brasil se encontra em todo o país, com exceção dos estados mais ao Sul.

Biologia. Os ninhos são conhecidos tanto de florestas úmidas como de matas semidecíduas, e operárias são capturadas com frequência correndo sobre o tronco de árvores. São conhecidas por serem rápidas e pelo ferrão potente. A reprodução é normalmente por meio de operárias férteis (gamergates). Contudo, o gênero se destaca pela variedade de formas de reprodução, talvez a mais diversa em toda a subfamília. Apenas na espécie $P$. punctata, presente no Brasil, existem rainhas aladas, ergatoides partenogenéticas, gamergates e operárias partenogenéticas (SCHMIDT; SHATTUCK, 2014).

Perspectiva. Os registros para este gênero são relativamente escassos e ainda é baixa a resolução dos padrões de distribuição das espécies conhecidas. Sabe-se da existência de vários exemplares em coleções que provavelmente representam espécies ainda não descritas, em particular do Caribe. Uma revisão do gênero seria bem-vinda,

FIGURA 11 - Exemplar do Platythyrea sinuata (Roger), operária. (a) cabeça em vista frontal e (b) corpo em vista lateral. Foto: Will Ericson (Antweb, CASENT0260485).

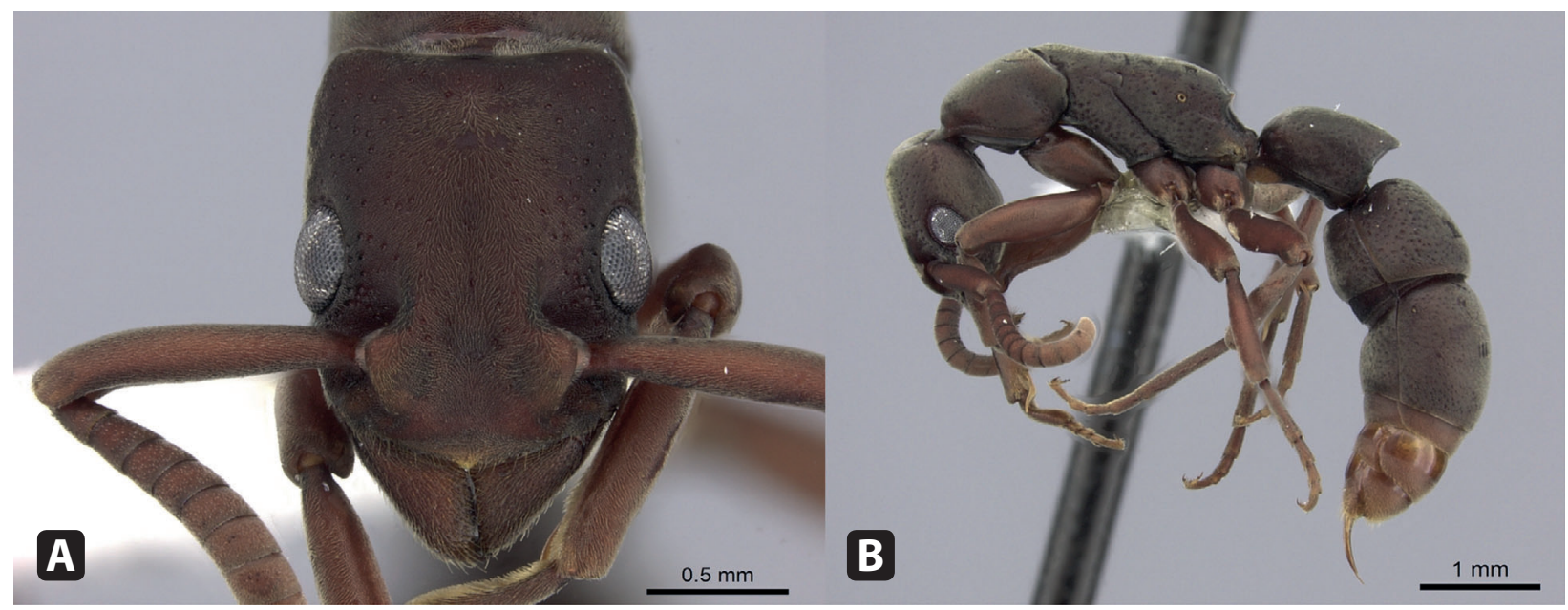


já que se passaram quase 40 anos desde o trabalho de Brown (1975), o último estudo taxonômico do gênero, o qual era muito preliminar.

\section{Pseudoponera Emery}

\section{Fig. 6.12}

Diagnose. Olho composto bem desenvolvido; mandíbula com um sulco, nunca uma fosseta, em sua base; em vista lateral, mesossoma com a margem dorsal contínua, com a sutura metanotal rasa; espiráculo propodeal em forma de fenda; ápice da metatíbia com dois esporões, um pectinado e um simples; pecíolo sem uma mancha translúcida em seu processo ventral.

Diversidade. Este gênero engloba seis espécies, quase que exclusivamente americanas, das quais três se encontram no Brasil. As espécies podem ser identificadas usando a revisão das Pachycondyla americanas de Mackay; Mackay (2010), onde figuram como parte do complexo stigma.

Distribuição. Este grupo tropical apresenta uma distribuição que vai desde o México até o Brasil e outra que vai da China à Austrália. Apenas uma espécie é exclusiva do Velho Mundo e P. stigma está presente em ambas as regiões, sendo aparentemente nativa do Neotrópico (WETTERER, 2012).

Biologia. São formigas predadoras de tamanho pequeno que vivem em florestas, nidificando em madeira em decomposição usualmente sobre o solo, mas também nas árvores.

Perspectiva. De todas as espécies, somente se sabe algo da biologia de $P$. stigma e quase nada das demais. Schmidt; Shattuck (2014) mencionam que estas formigas carecem de sinapomorfias inequívocas para apoiar sua identidade como gênero e que apresentam uma relação próxima aos gêneros paleotropicais Parvaponera e Austroponera, mas ainda é necessário estabelecer a monofilia de cada grupo.

\section{Rasopone Schmidt; Shattuck}

Fig. 6.13

Diagnose. As operárias apresentam olhos localizados anteriormente na cabeça, mandíbulas triangulares bem desenvolvidas com sete a doze dentes e sem um sulco ou fosseta em sua base. A sutura metanotal é obsoleta; abertura do espiráculo propodeal redonda a oval e o orifício da glândula metapleural não possui uma franja cuticular em forma de "U" invertido; metatíbia com dois esporões apicais. Processo ventral do pecíolo sem uma mancha translúcida; estridulito ausente entre o terceiro e quarto segmentos abdominais, ao observar esta região não se encontra uma franja longitudinal que refrata a luz (SCHMIDT; SHATTUCK, 2014).

Diversidade. Na revisão de Mackay; Mackay (2010), as 11 espécies americanas deste gênero são

FIGURA 6.12 - Exemplar do Pseudoponera stigma (Fabricio), operária. (a) cabeça em vista frontal e (b) corpo em vista lateral. Foto: April Nobile (Antweb, CASENT0178180).

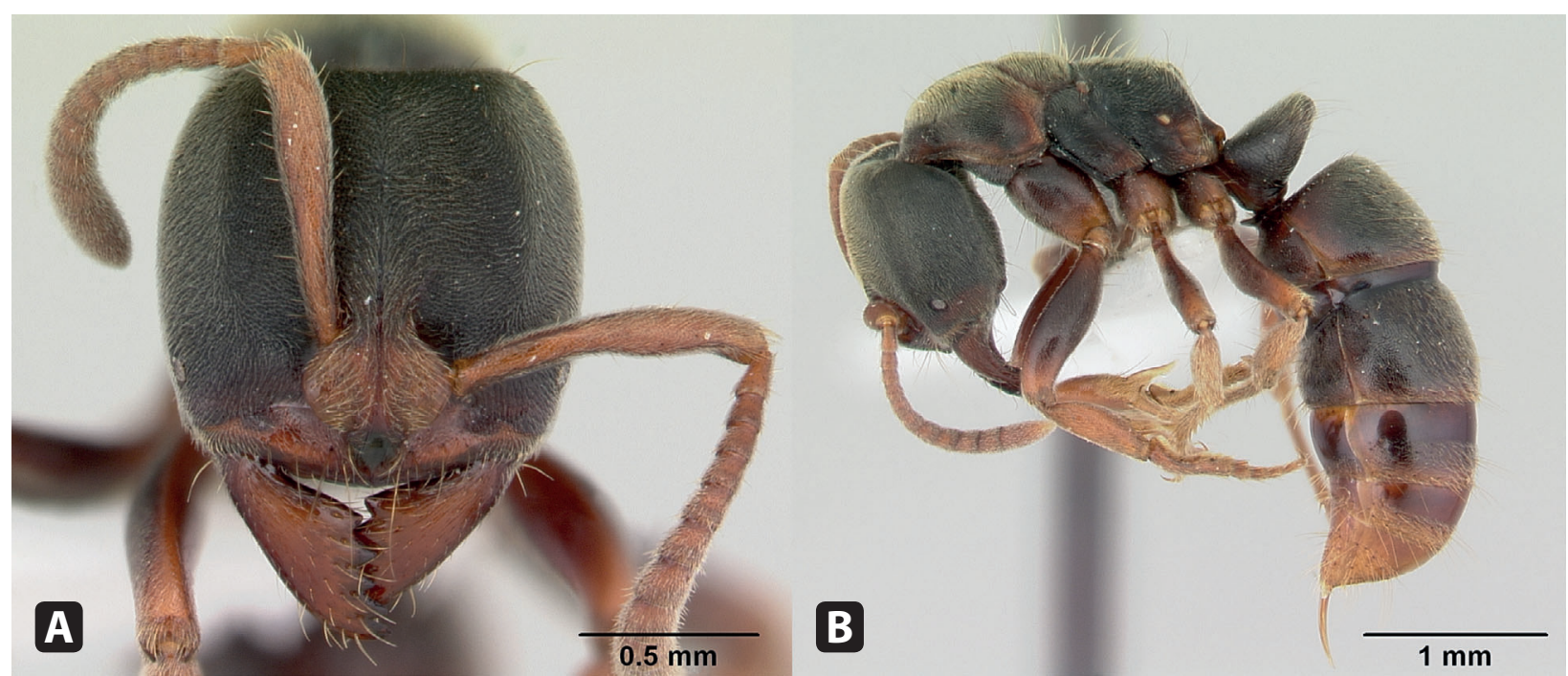


FIGURA 6.13 - Exemplar do Rasopone becculata (MacKay; MacKay, 2010), operária. (a) cabeça em vista frontal e (b) corpo em vista lateral. Foto: Ryan Perry (Antweb, CASENT0249130).

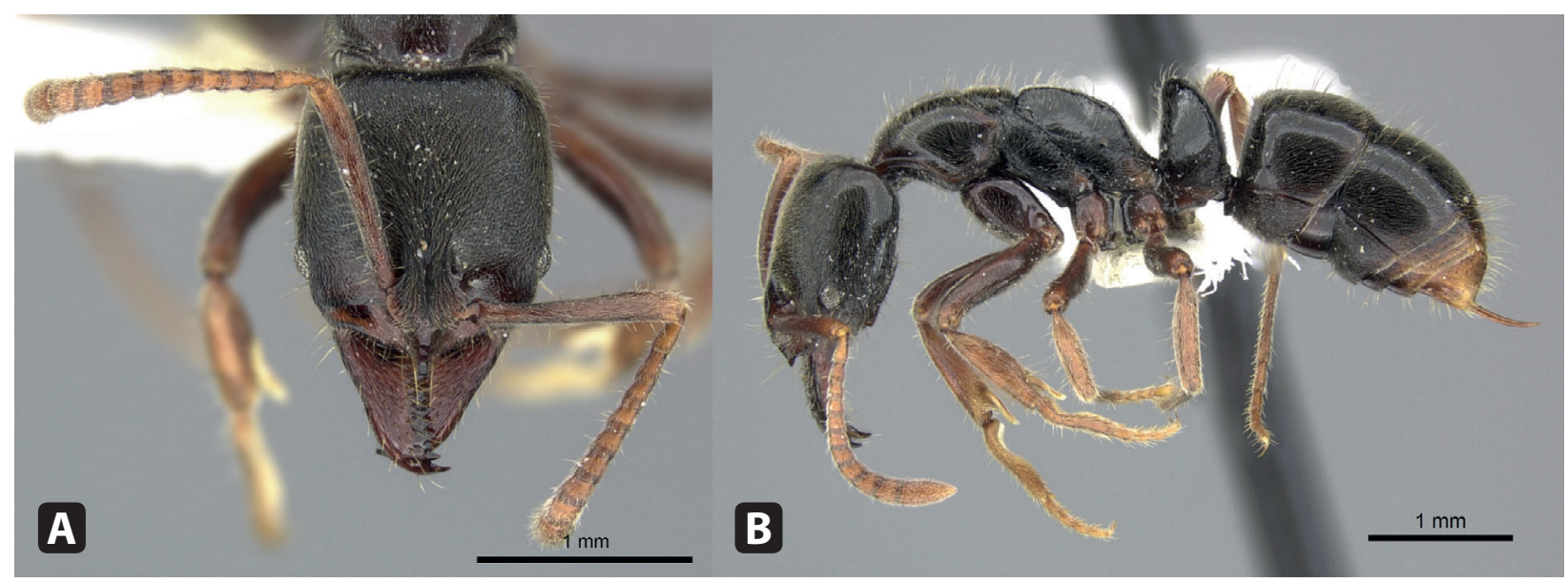

tratadas como o complexo ferruginea e arhuaca de Pachycondyla. Estão registradas três espécies para o Brasil, das quais a maioria dos exemplares são $R$. arhuaca ou $R$. ferruginea, as duas espécies mais comuns.

Distribuição. Este gênero é exclusivamente americano, encontrado do México ao Peru, Bolívia e Sul do Brasil. Membros deste gênero se encontram dispersos por quase todo o país, exceto por algumas partes do Nordeste.

Biologia. Os ninhos se encontram no solo e em madeira decomposta, especialmente em ambientes de floresta, incluindo cacauais e cafezais sombreados. São coletadas em amostras de serapilheira peneirada (MACKAY; MACKAY, 2010; SCHMIDT; SHATTUCK, 2014).

Perspectivas. O que se sabe da biologia provém de algumas observações esporádicas já que não há estudos detalhados sobre nenhuma espécie. São necessárias amostras de solo para uma melhor resolução da distribuição no país, mas em particular para delimitar as regiões onde o grupo aparentemente não está representado, como o Nordeste ou Santa Catarina.

\section{Simopelta Mann}

Fig. 6.14

Diagnose. As mandíbulas são subtriangulares com dois dentes apicais agudos usualmente separados dos demais por um espaço; clípeo consideravelmente elevado em comparação à superfície mandibular; olhos frequentemente reduzidos a um único omatídeos. Orifício da glândula metapleural com uma franja cuticular posterior em forma de " $U$ " invertido; tíbias sem setas robustas sobre sua face externa; presença de um arólio proeminente entre as garras tarsais.

Diversidade. São conhecidas 21 espécies para este gênero neotropical, das quais quatro estão registradas para o Brasil. As espécies podem ser identificadas através da revisão de MACKAY; MACKAY (2008).

Distribuição. Estas formigas são encontradas desde a Guatemala até o Peru e Brasil.

Biologia. Normalmente são encontradas em florestas montanhosas entre 800 - 2.000 m.a.n.m., onde se adaptaram a um modo de vida nômade, semelhante ao das formigas dorilíneas, o que inclui a presença de rainhas ápteras e com gáster hipertrofiado, aparente sincronização de crescimento da prole e ninhos estacionais. São predadoras de outras formigas, em especial Pheidole.

Perspectivas. É de se esperar que ainda existam espécies a serem descritas, considerando que há pelo menos quatro novas espécies reconhecidas por LONGINO (2014) na Costa Rica. A convergência da biologia entre estas formigas e as dorilíneas as torna candidatas para estudos detalhados de comportamento, como ocorre com Eciton burchellii ou Eciton hamatum. Contudo, até o momento, são muito restritas as pesquisas sobre Simopelta (KRONAUER 
FIGURA 6.14 - Exemplar do Simopelta transversa Mackay; Mackay, 2008, operária. (a) cabeça em vista frontal e (b) corpo em vista lateral. Foto: Zach Lieberman (Antweb, CASENT0915306).

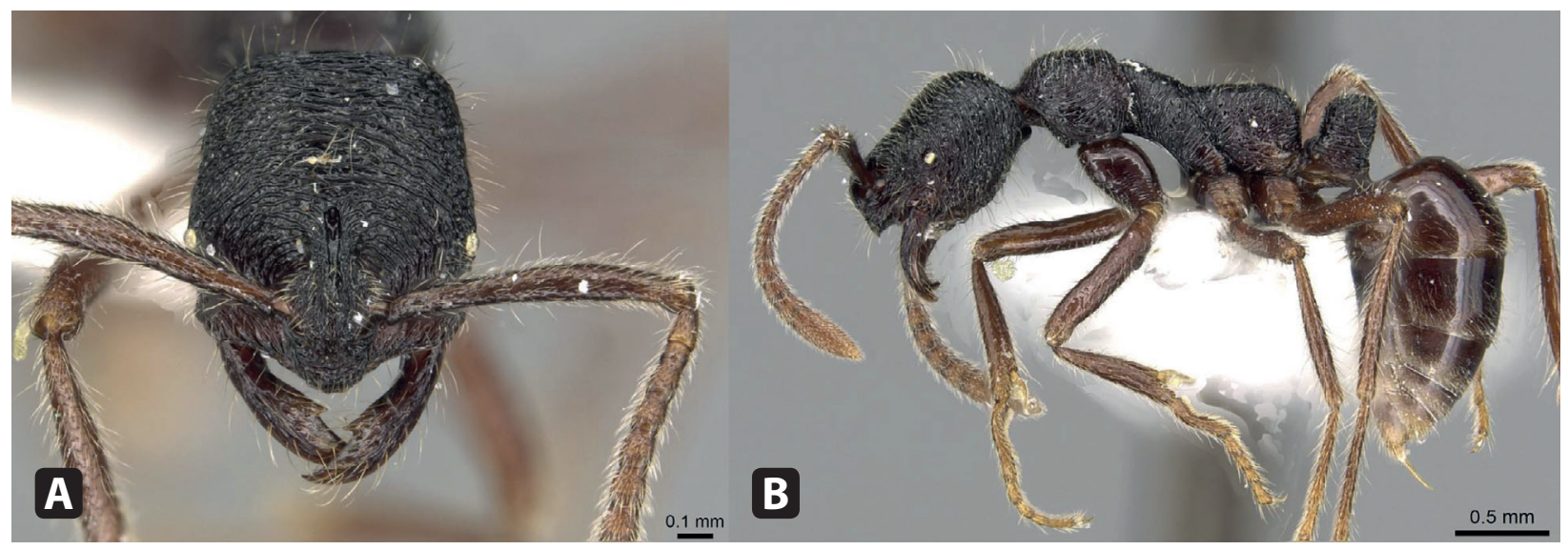

et al., 2011). Os machos permaneceram desconhecidos por muito tempo, mas, mais recentemente, exemplares têm sido coletados e relacionados a diferentes espécies, alguns dos quais com imagens disponíveis no Antweb. Espera-se que estes e outros machos sejam descritos pelo pesquisador Brendon Boudinot, estudante no laboratório de Philip Ward e que estuda a morfologia e sistemática de machos de formigas como parte de seu doutorado.

\section{Thaumatomyrmex Mayr}

\section{Fig. 6.15}

Diagnose. A cabeça é mais larga do que longa em vista frontal, cada mandíbula e seus três dentes são alongados e estreitos, com aparência de garfo e estão inseridas em projeções laterais da margem anterior da cabeça; as inserções antenais estão bem separadas pela porção posterior do clípeo, muito mais do que em qualquer outra ponerínea; olhos compostos relativamente grandes e convexos, situados aproximadamente na metade da altura da cabeça. As mandíbulas são o suficiente para se reconhecer o gênero.

Diversidade. São conhecidas 12 espécies para o gênero (BOLTON, 2014), das quais apenas duas são conhecidas para o Brasil. A taxonomia do grupo não é fácil e ainda há muitas situações duvidosas quanto à identidade de algumas espécies. Podem ser identificadas com a chave em Fernández (2008).

Distribuição. O gênero é endémico da Região Neotropical, onde é encontrado desde o México até a Bolívia e Brasil, incluindo o Caribe.
Biologia. Estas predadoras especializadas são coletadas com pouca frequência em áreas de floresta, aparentemente com uma preferência por florestas estacionais. Os ninhos têm poucos indivíduos, menos de 10, e são encontrados sob a casca de árvores, madeira em decomposição, serapilheira, conchas vazias de gastrópodes e até em vespeiros abandonados (SCHMIDT; SHATTUCK, 2014). Os enormes dentes mandibulares servem para remover os pelos urticantes de sua presa, diplópodos polixenídeos. Depois de subjugar a presa e imobilizá-la com sua ferroada, usam estruturas nas pernas anteriores para "depilar" os diplópodos e assim poderem oferecê-los às suas larvas (BRANDÃO et al., 1991). Informações substanciais sobre a biologia e taxonomia destas formigas são encontradas no trabalho de Jahyny et al. (2008).

Perspectivas. A taxonomia alfa ainda apresenta desafios quanto à definição de algumas espécies conhecidas e a descrição de novas espécies, apesar dos esforços de Longino (1988) e Jahyny et al. (2008). Uma revisão que combinasse dados morfológicos e moleculares seria muito esclarecedora.

\section{Perspectivas quanto ao estudo de Ponerinae}

O futuro é promissor. Há uma atividade crescente, novos recursos humanos e apoio institucional à pesquisa. Grupos de trabalho e equipes de pesquisadores têm sido criados e têm cooperado entre si tanto no Brasil como no exterior. Cada edição do Simpósio de Mirmecologia demonstra 
FIGURA 6.15 - Exemplar do Thaumatomyrmex sp., operária. (a) cabeça em vista frontal e (b) corpo em vista lateral. Foto: April Nobile (Antweb, CASENT173032).

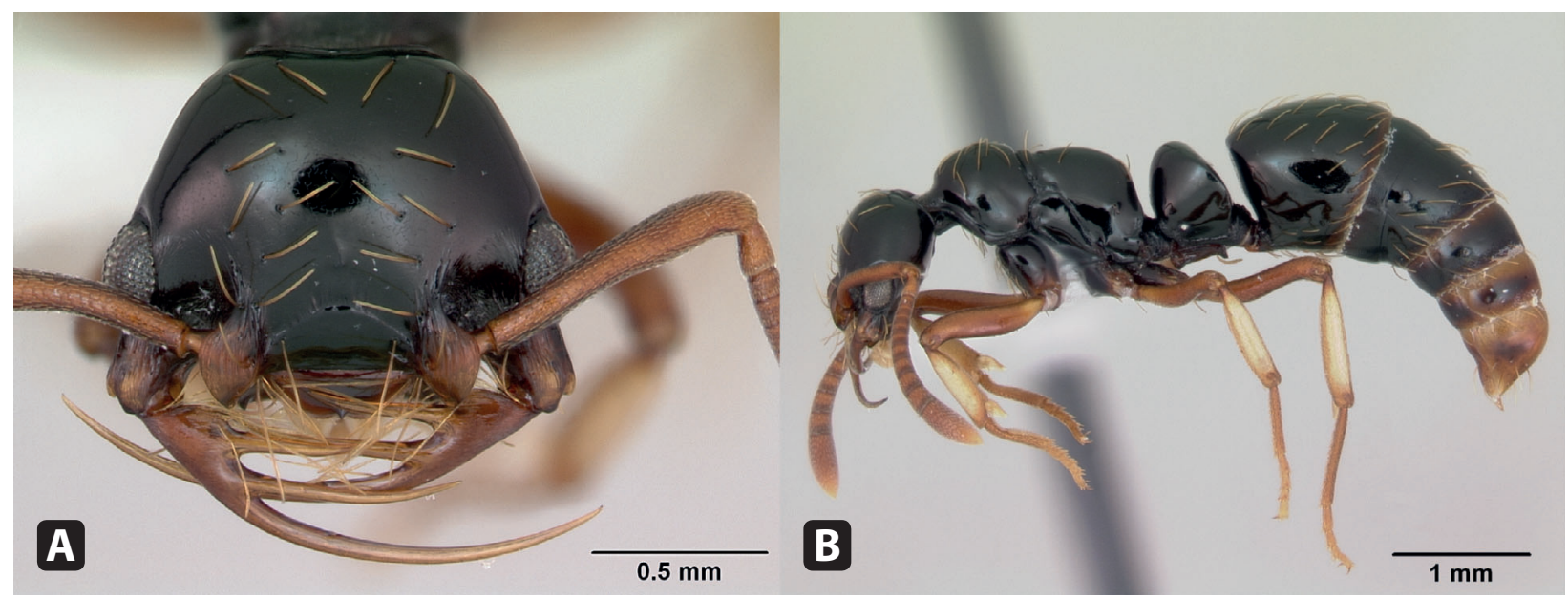

um crescente dinamismo de trabalhos sobre poneríneas e outras formigas. Cursos e oficinas, assim como a edição de obras como a presente, não seriam possíveis sem uma combinação de recursos tanto materiais quanto humanos muito oportunos. Apesar da quantidade nada desprezível de estudos e outros esforços realizados sobre este grupo de formigas, ainda persistem muitas lacunas e problemas por resolver. Tentarei cobrir alguns destes pontos sem que a ordem de menção sugira alguma prioridade.

Não temos uma chave para identificar os gêneros dos machos de poneríneas na América. Isto significa um atraso e obstáculo no estudo de muitos aspectos da ecologia da subfamília. Felizmente, Brendon Boudinot, estudante de doutorado na Universidade da Califórnia em Davis, está solucionando este problema. Por outro lado, não existe uma filogenia nem ao menos medianamente detalhada para nenhum gênero do grupo, exceto Leptogenys (LATTKE, 2011), e mesmo esta proposta cobre apenas a fauna americana e sua resolução deixa muito a desejar. Schmidt (2013), em seu estudo molecular da subfamília, pôde apenas amostrar algumas espécies de cada gênero, mas não era o objetivo desse trabalho fazer uma filogenia completa de cada gênero.

Em geral, ainda falta muito a se fazer na taxonomia alfa da maioria dos grupos, ainda que alguns possuam revisões relativamente recentes. Já se passaram mais de 40 anos desde as revisões fundamentais de William Brown nos anos $60 \mathrm{e}$ 70, e já é tempo de se retomar a taxonomia destes grupos. Contudo, não temos informação sólida de como são os padrões de distribuição da maioria das espécies e menos ainda de sua biologia. Muito disto implica em expedições de coleta e estudos de história natural, atividades clássicas e muito necessárias. A queda nos custos e a facilidade de acesso a técnicas de amostragem e análises de dados moleculares progressivamente alimentarão e guiarão cada vez mais os estudos de diversidade. Este é um complemento valiosíssimo dos estudos utilizando morfologia, onde as descobertas fortalecem mutuamente os dois enfoques. As formigas não são imunes a problemas como as mudanças climáticas, destruição de habitats e espécies invasoras, de modo que é de se esperar que extinções e outros problemas surjam com o tempo. Estes problemas impactarão de maneira mais severa espécies endêmicas e grupos que se reproduzem sem rainhas aladas. $\mathrm{O}$ número crescente de centros urbanos oferece novas oportunidades para o estudo das interações de formigas em ambientes alterados.

Por último, também existem os problemas potenciais associados às políticas de estado e ao estágio de desenvolvimento de nossas sociedades. As oscilações socioeconômicas e seus efeitos sobre a vida cotidiana dos pesquisadores, docentes e estudantes têm seu impacto sobre a pesquisa ao afetar áreas como a estabilidade acadêmica, acesso a equipamentos e materiais, segurança pessoal, ingerências político-partidárias e qualidade de vida. No pior cenário, estes fatores podem atrasar, dificultar e em casos extremos destruir a atividade acadêmica e seus acervos na nossa América. Não devemos perder de vista os fatores que cercam a vida acadêmica. 
Agradecimentos. Agradeço aos editores deste livro pelo gentil convite para integrar o grupo de autores. É uma honra estar entre profissionais de tanta qualidade e poder contribuir para a compreensão da vasta biodiversidade do Brasil, e consequentemente da nossa América. Agradeço a Rodrigo Feitosa pela cuidadosa tradução ao Português do original em castelhano.

\section{Referências}

ANDRADE, M. L. DE. A new species of Platythyrea from Dominican amber and description of a new extant species from Honduras (Hymenoptera: Formicidae). Revue Suisse de Entomologie, v. 111, n. 3, p. 643-655, 2004.

BOLTON, B. Synopsis and Classification of the Formicidae. Memoirs of the American Entomological Institute, v. 71, p. 1-357, 2003.

BOLTON, B. An online catalog of the ants of the world. Disponível em: $<$ http://antcat.org $>$. Acesso em: 15.11.2014.

BRANDÃO, C. R. F.; DINIZ, J. L. M.; TOMOTAKE, E. M. Thaumatomyrmex strips millipedes for prey: a novel predatory behaviour in ants, and the first case of sympatry in the genus (Hymenoptera: Formicidae). Insectes Sociaux, v. 38, p. 335-344, 1991.

BROWN, W.L., J. Contributions toward a reclassification of the Formicidae. V. Tribes Platythyreini, Cerapachyini, Cylindromyrmecini, Acanthostichini, and Aenictogitini. Search: Agriculture, Cornell University, v. 5, n. 1, p. $1-115,1975$.

BROWN, W.L., J. Contributions toward a reclassification of the Formicidae. Part VI. Ponerinae, Tribe Ponerini, Subtribe Odontomachiti. Section A. Introduction, Subtribal Characters, Genus Odontomachus. Studia Entomologica, v. 19, p. 67-174, 1976.

BROWN, W.L., J. Contributions toward a Reclassification of the Formicidae. Part VI. Ponerinae, Tribe Ponerini, Subtribe Odontomachiti. Section B. Genus Anochetus and Bibliography. Studia Entomologica, v. 20, p. 549-652, 1978.

DELABIE, J. H. C. Inquilinismo simultâneo de duas espécies de Centromyrmex em cupinzeiros de Syntermes. Revista Brasileira de Entomologia, v. 39, n. 3, p. 605-609, 1995.

DELABIE, J. H. C.; BLARD, F. The tramp ant Hypoponera punctatissima (Roger) (Hymenoptera : Formicidae : Ponerinae): New Records from the Southern Hemisphere. Neotropical entomology, v. 31, n. 1, p. 1999-2001, 2002.
FEITOSA, R. M.; LACAU, S.; ROCHA, W. D. DA; OLIVEIRA, A. R.; DELABIE, J. H. C. A giant new arboreal species of the ant genus Anochetus from Brazil (Formicidae: Ponerinae). Annales de la Société Entomologique de France, v. 48, n. 3-4, p. 253-259, 2012. Disponível em: <http://www.tandfonline.com/doi/abs/10. 1080/00379271.2012.10697774>. Acesso em: 1/9/2014.

FERNANDES, I. O.; OLIVEIRA, M. L. DE; DELABIE, J. H. C. Description of two new species in the Neotropical Pachycondyla foetida complex (Hymenoptera: Formicidae: Ponerinae) and taxonomic notes on the genus. Myrmecological News, v. 19, p. 133-163, 2014.

FERNANDEZ, F. Subfamilia Ponerinae s. str. In: E. Jimenez; F. Fernandez; T. M. Arias; F. H. LozanoZambrano (Eds.); Sistemática, biogeografía y conservación de las hormigas cazadoras de Colombia. p.124-218, 2008. Bogota: Instituto de Investigación de Recursos Biológicos Alexander von Humboldt.

FERNÁNDEZ, F.; SENDOYA, S. List of Neotropical ants (Hymenoptera: Formicidae). Biota Colombiana, v. 5, n. 1, p. 3-93, 2004.

FERREIRA, R. S.; POTEAUX, C.; DELABIE, J. H. C.; FRESNEAU, D.; RYBAK, F. Stridulations reveal cryptic speciation in neotropical sympatric ants. PloS One, v. 5, n. 12, p. e15363, 2010. Disponível em: $<$ http://www.pubmedcentral.nih.gov/articlerender. fcgi?artid=3008743\&tool=pmcentrez\&rendertype $=$ abstract $>$. Acesso em: 21/11/2014

JAHYNY, B.; LACAU, S.; DELABIE, J. H. C.; FRESNEAU, D. Le genre Thaumatomyrmex Mayr 1887, cryptique et prédateur spécialiste de Diplopoda Penicillata. In: E. Jiménez; C. Fernández; T. M. Arias; F. H. Lozano-Zambrano (Eds.); Sistemática, biogeografía y conservación de las hormigas cazadoras de Colombia. p.329-346, 2008. Instituto de Investigación de Recursos Biológicos Alexander von Humboldt.

JIMÉNEZ, E; FERNÁNDEZ, F; ARIAS, T.M.; LOZANOZAMBRANO, F.H. (Eds.); Sistemática, biogeografía y conservación de las hormigas cazadoras de Colombia. 2008. Bogota: Instituto de Investigación de Recursos Biológicos Alexander von Humboldt.

KEMPF, W. W. A synopsis of the Neotropical ants of the genus Centromyrmex Mayr (Hymenoptera: Formicidae). Studia Entomologica, v. 9, n. 1-4, p. 401-410, 1967.

KRONAUER, D. J. C.; O'DONNELL, S.; BOOMSMA, J. J.; PIERCE, N. E. Strict monandry in the ponerine army ant genus Simopelta suggests that colony size and complexity drive mating system evolution in social insects. Molecular Ecology, v. 20, n. 2, p. 420-8, 2011. Disponível em: <http://www.ncbi.nlm.nih.gov/ pubmed/21121990>. Acesso em: 23/11/2014. 
LATTKE, J. E. Revision of the New World species of the genus Leptogenys Roger ( Insecta : Hymenoptera : Formicidae : Ponerinae ). Arthropod Systematics; Phylogeny, v. 69, n. 1975, p. 127-264, 2011.

LENHART, P. A.; DASH, S. T.; MACKAY, W. P. A revision of the giant Amazonian ants of the genus Dinoponera (Hymenoptera, Formicidae). Journal of Hymenoptera Research, v. 164, p. 119-164, 2013.

LONGINO, J. T. Notes on the taxonomy of the Neotropical ant genus Thaumatomyrmex Mayr (Hymenoptera: Formicidae). In: J.C. Trager (Ed.); Advances in Myrmecology. p. 35-42, 1988. Leiden: E. J. Brill, xxvii + 551 pp.

LONGINO, J.T. Ants of Costa Rica. Simopelta species list. 2009. Disponível em: <http://academic.evergreen. edu/projects/ants/genera/SIMOPELTA/Specieslist. html >. Acesso em: 15/11/2014.

MACKAY, W. P.; MACKAY, E. Revision of the ants of the genus Simopelta Mann. In: E. Jiménez; F. Fernández; T. M. Arias; F. H. Lozano-Zambrano (Eds.); Sistemática, biogeografía y conservación de las hormigas cazadoras de Colombia. p.285-328, 2008. Bogota: Instituto de Investigación de Recursos Biológicos Alexander von Humboldt.

MACKAY, W.P.; MACKAY, E. The systematics and biology of the New World ants of the genus Pachycondyla. Lewiston: Edwin Mellen Press, 2010.
SCHMIDT, C. Molecular phylogenetics of ponerine ants (Hymenoptera: Formicidae: Ponerinae). Zootaxa, v. 3647, p. 201-250, 2013.

SCHMIDT, C. A.; SHATTUCK, S. O. The higher classification of the ant subfamily Ponerinae (Hymenoptera: Formicidae), with a review of ponerine ecology and behavior. Zootaxa, v. 3817, n. 1, p. 1-242, 2014. Disponível em: <http://www.ncbi.nlm.nih.gov/ pubmed/24943802>.

SEIFERT, B. Hypoponera ergatandria (Forel , 1893) - a cosmopolitan tramp species different from H. punctatissima (Roger, 1859) (Hymenoptera: Formicidae). Soil Organisms, v. 85, n. December, p. 189-201, 2013. Disponível em: <http://www. senckenberg.de/root/index.php?page_id=17139>. .

TILLBERG, C. V; EDMONDS, B.; FREAUFF, A.; et al. Foraging ecology of the tropical giant hunting ant Dinoponera australis (Hymenoptera: Formicidae) - Evaluating Mechanisms for High Abundance. Biotropica, v. 46, n. 2, p. 229-237, 2014.

WETTERER, J. K. Worldwide spread of the stigma ant, Pachycondyla stigma ( Hymenoptera : Formicidae ). Myrmecological News, v. 16, p. 39-44, 2012. 